Article

\title{
Integrated Application of Rapeseed Cake and Green Manure Enhances Soil Nutrients and Microbial Communities in Tea Garden Soil
}

\author{
Haiping Fu ${ }^{1,2,+}$, Huan Li ${ }^{3,+}$, Peng Yin ${ }^{2}$, Huiling Mei ${ }^{4}$, Jianjie Li ${ }^{4}$, Pinqian Zhou ${ }^{1}$, Yuanjiang Wang ${ }^{1}$, \\ Qingping Ma ${ }^{5}$, Anburaj Jeyaraj ${ }^{5}$, Kuberan Thangaraj ${ }^{5} \mathbb{D}$, Xuan Chen ${ }^{5} \mathbb{D}$, Xinghui Li ${ }^{5, *}$ and Guiyi Guo ${ }^{2, *}$ \\ 1 Tea Research Institute, Hunan Academy of Agricultural Sciences, Changsha 410126, China; \\ fuhaiping2010@126.com (H.F.); xniancier@163.com (P.Z.); chnwyj@163.com (Y.W.) \\ 2 Henan Key Laboratory of Tea Comprehensive Utilization in South Henan, Xinyang Agriculture and \\ Forestry University, Xinyang 464000, China; 52greentea@sina.com \\ 3 Institute of Leisure Agriculture, Jiangsu Academy of Agricultural Sciences, Nanjing 210014, China; \\ 20170032@jaas.ac.cn \\ 4 College of Resources and Environmental Sciences, Nanjing Agricultural University, Nanjing 210095, China; \\ 2019203030@njau.edu.cn (H.M.); 2019203032@njau.edu.cn (J.L.) \\ 5 Tea Research Institute, Nanjing Agricultural University, Nanjing 210095, China; \\ maqingpingtea@163.com (Q.M.); tku2010@gmail.com (A.J.); geneanbu1986@gmail.com (K.T.); \\ chenxuan@njau.edu.cn (X.C.) \\ * Correspondence: 1xh@njau.edu.cn (X.L.); ggy6363@aliyun.com (G.G.); Tel.: +86-25-8439-6651 (X.L.); \\ +86-376-668-7756 (G.G.) \\ $+\quad$ These authors have contributed equally to this study.
}

Citation: Fu, H.; Li, H.; Yin, P.; Mei, H.; Li, J.; Zhou, P.; Wang, Y.; Ma, Q.; Jeyaraj, A.; Thangaraj, K.; et al. Integrated Application of Rapeseed Cake and Green Manure Enhances Soil Nutrients and Microbial Communities in Tea Garden Soil. Sustainability 2021, 13, 2967. https://doi.org/10.3390/su13052967

Academic Editor: Domenico Ronga

Received: 16 January 2021

Accepted: 5 March 2021

Published: 9 March 2021

Publisher's Note: MDPI stays neutral with regard to jurisdictional claims in published maps and institutional affiliations.

Copyright: (c) 2021 by the authors. Licensee MDPI, Basel, Switzerland. This article is an open access article distributed under the terms and conditions of the Creative Commons Attribution (CC BY) license (https:// creativecommons.org/licenses/by/ $4.0 /)$
Abstract: (1) Aims: This study was aimed to investigate the effects of organic and inorganic fertilizer application on the soil nutrients and microbiota in tea garden soil. (2) Method: Illumina Hiseq sequencing technique was conducted to analyze the microbial diversity and density in different fertilizer-applied tea garden soil. (3) Results: The results showed that Acidobacteria, Proteobacteria and Actinobacteria were the predominant bacterial species observed in the tea garden soil. Besides, the relative abundance of Basidiomycota, Ascomycota and Zygomycota fungal species were higher in the tea garden soil. Correlation analysis revealed that Acidibacter and Acidothermus were significantly correlated with chemical properties (such as total organic carbon (TOC), total phosphorus (TP) and available phosphorus (AP) contents) of the tea garden soil. Furthermore, all these microbes were abundant in medium rapeseed cake (MRSC) + green manure (GM) treated tea garden soil. (4) Conclusion: Based on the obtained results, we conclude that the application of MRSC + GM could be a preferred fertilizer to increase the soil nutrients (TOC, TP and AP content) and microbial population in the tea garden soil.

Keywords: fertilizer; green manure; microbiota; rapeseed cake; soil nutrient

\section{Introduction}

Soil is a complicated ecosystem providing many environmental and agriculture services including food for almost every organism on earth [1]. The nitrogen fertilizer application causes complex effects on soil properties such as soil chemical, biological and physical conditions, and even on the degradation of the soil quality and reduction plant productivity [2]. Soil microorganisms play an important role in cycling nutrients and the energy flow [3], while bacteria and fungi have essential impacts on physical and chemical conditions of soil [4]. It is known that community structure, diversity and abundance of soil microorganisms are sensitive to the land usage and soil management [5]. Therefore, it is important to understand the dynamics of the soil microbial community.

Tea plants (Camellia sinensis (L.) O. Kuntze), a famous perennial evergreen woody economic crop in the world that grow well in acidic soils with $\mathrm{pH}$ range from four to six. 
are widely distributed in tropical and subtropical places of China [6]. China is the largest tea producer in the world with $1.76 \times 10^{6}$ hectares of tea plant area and $1.94 \times 10^{6}$ ton of yield in 2013 [7]. However, soil deterioration has been observed in long-term monoculture of tea plants, which, in turn, has led to massive output reduction of tea [8]. Presently, a lot of nitrogen fertilizers which can reach $2000 \mathrm{~kg} \mathrm{~N} \mathrm{ha}^{-1}$ in some areas of China and Japan have been applied to stabilize the economic benefits of tea. Soil acidification is aggravated as a result of leaching of acidic ions [9]. Three elements have been considered to alter the soil quality of tea rhizosphere, including the changes in microbial community structure, soil physical and chemical properties [10]. Moreover, the deficiency of soil nutrient availability can seriously affect the physiological condition, vitality and community structure of rhizosphere microorganism in tea garden, which influence the yield and quality of tea.

In the present investigation, Illumina Hiseq sequencing approach was used to evaluate the abundance and the structure of microbiota in tea garden soil that was being exposed to different fertilizer applications over 3 years. Additionally, the soil nutrient parameters were also detected and analyzed to evaluate the effect of different fertilizer on soil properties and tea productivity and quality. Based on the results, a better fertilizer combination would be proposed for improving the ecological sustainability of tea orchard ecosystem.

\section{Materials and Methods}

\subsection{Experiment Design and Fertilizer Treatment}

The experiment was conducted in Gaoqiao of Hunan Province $\left(113^{\circ} 19^{\prime}\right.$ E, $28^{\circ} 29^{\prime} \mathrm{N}$, 68 MSL with an annual rain of $1380 \mathrm{~mm}$ ) in 2015. Camellia sinensis cv. Fuding Dabai was planted in the experimental field. The field management, pest control and other management measures of each plot are the same to ensure the normal growth of tea trees. The soil samples used in this research are treated with the following treatments and the details, namely, zero fertilizer (CK), chemical fertilizer (CF, $450 \mathrm{~kg} / \mathrm{ha}$ ), rapeseed cake (RSC, $6750 \mathrm{~kg} / \mathrm{ha}), \mathrm{RSC}+\mathrm{CF}(6750+180 \mathrm{~kg} / \mathrm{ha})$, low RSC + green manure (LRSC + GM, $2250+36,000 \mathrm{~kg} / \mathrm{ha})$, medium RSC + GM (MRSC + GM, $4500+36,000 \mathrm{~kg} / \mathrm{ha})$ and high $\mathrm{RSC}+\mathrm{GM}(\mathrm{HRSC}+\mathrm{GM}, 6750+36,000 \mathrm{~kg} / \mathrm{ha})$. Among the tested fertilizers, urea $\left(\mathrm{CH}_{4} \mathrm{~N}_{2} \mathrm{O}\right)$ was the chemical fertilizer, and rapeseed cake was the by-product of Changsha local rapeseed after being pressed, $\mathrm{N}: 6.24 \% ; \mathrm{P}_{2} \mathrm{O}_{5}: 2.65 \% ; \mathrm{K}_{2} \mathrm{O}: 1.71 \%$. Green manure is a green manure variety chafei $1^{\#}$ bred by Hunan Tea Research Institute.

Each treatment has three replicates with randomized block design. In the present study, the soil samples were treated with various combinations of organic and inorganic fertilizers. After the application the soil samples were collected and the nutrient content and microbial population in the samples were analyzed.

\subsection{Soil Physicochemical Analysis}

In May 2018, soil samples from 0-20 cm soil layers of tea garden were collected by 5-point sampling method in each experimental plot. The soil samples for all the treatments were collected and stored at $-80^{\circ} \mathrm{C}$ for further analysis. Soil $\mathrm{pH}$ and available nitrogen (AN) were measured by a combination $\mathrm{pH}$ electrode (soil: Water, 1:2.5 $w / v$ ) and alkaline hydrolysable method [11], respectively. Total nitrogen (TN) and total organic carbon (TOC) were measured by Kjeldahl digestion [12], total potassium (TK) and total phosphorus (TP) were determined by $\mathrm{NaOH}$ melt flamer and sodium carbonate method, respectively [13,14]. Available phosphorus (AP) and available potassium (AK) were extracted by hydrochloric acid and flame photometry, respectively [15].

\subsection{DNA Extraction, Amplification and Pyrosequencing Analysis}

The microbial consortia of organic and inorganic fertilizer treated soil samples were analyzed by Hiseq sequencing approach. Bacterial and fungal DNA was extracted from the soil samples by using OMEGA E.Z.N.A soil DNA kit (Norcross, GA, USA) according to the manufacturer's instructions [16] and the DNA quality was detected by $1.2 \%$ agarose 
gel electrophoresis. To identify the fungal diversity in the tea garden soil, the extracted sequences were amplified with primer pairs (5'-CTTGGTCATTTAGAGGAAGTAA-3 ${ }^{\prime}$ ) and (5'-GCTGCGTTCTTCATCGATGC-3') that's amplify ITS1 and ITS4 regions of internal transcribed spacer (ITS). Meanwhile, primers pair, 515F (5'-GTGCCAGCMGCCGCGGTAA-3') and 806R ( $5^{\prime}$-GGACTACHVGGGTWTCTAAT-3') were amplify V3-V4 region of the $16 \mathrm{~S}$ rRNA to detect the bacterial diversity in the tea garden soil. The PCR was conducted with the following cycling parameters: $95^{\circ} \mathrm{C}$ for 2 min as initial denaturation, 35 cycles of $95^{\circ} \mathrm{C}$ for $30 \mathrm{~s}, 55^{\circ} \mathrm{C}$ for $1 \mathrm{~min}, 72{ }^{\circ} \mathrm{C}$ for $1 \mathrm{~min}$ and a final extension at $72{ }^{\circ} \mathrm{C}$ for $10 \mathrm{~min}$. The purified PCR products were used for DNA library construction using TruSeq ${ }^{\circledR}$ DNA PCR-free sample preparation kit. After assessing the DNA quality, the DNA library was sequenced on Illumina HiSeq platform provided by Beijing Genomics Institute (Shenzhen, China).

\subsection{Bioinformatics and Statistical Analysis}

All 250 bp pair-end reads were connected using Connecting Overlapped Pair-end software (COPE, V 1.2.1) [17] after removing barcodes and adaptor sequences. The quality of the raw tags were controlled by trimming low quality sequences using Qiime V1.9.1 (http:/ / qiime.org/scripts/split_libraries_fastq.html (accessed on 14 May 2018)) [18]. Finally, the effective tags were obtained after detecting and removing chimera by UCHIME Algorithm (http: / / www.drive5.com/usearch/manual/uchime-algo.html (accessed on 1 October 2017)) and Unite database (https:/ / unite.ut.ee/ (accessed on 5 April 2018)) respectively $[19,20]$. The effective tags were used for further analysis. Effective tags were clustered into operational taxonomic units (OTUs) by using Uparse software (http:/ / drive5.com/uparse/ (accessed on 1 October 2017)) [21]. The typical OTUs were annotated by blast analysis using Qiime software and Unit database (https:/ / unite.ut.ee/ (accessed on 5 April 2018)) [22]. Multiple sequence alignment was conducted by MUSCLE V3.8.31 (http:/ /www.drive5.com/muscle/ (accessed on 5 April 2018)) [23]. Community richness and diversity indices such as Chao 1, Shannon diversity and Simpson diversity indices were calculated by Qiime software. Diversity differences between samples were assessed by T test and Wilcox test. The Spearman's rank-bacteria correlation was used to investigate the correlation between the soil properties and the abundant genera. Differences of multiple comparisons were detected by R software with Tukey and Wilcox of agricolae package (https:/ / www.r-project.org/ (accessed on 5 April 2018)) for abundance and diversity of bacterial and fungal species. Soil physicochemical properties analysis was conducted using SPSS 23.0 software package and the significant differences were assessed by One-way ANOVA analysis. $p<0.05$ was considered as significant difference.

\section{Results}

\subsection{Soil Physicochemical Analysis}

In zero fertilizer application tea garden, the soil $\mathrm{pH}$ was significantly higher than in the fertilized tea garden soil. Particularly, the alkali-hydrolyzable nitrogen (AHN) was significantly higher in the fertilizer applied tea garden soil compared to zero fertilizer applied tea garden soil. Besides, there is no significant differences observed in $\mathrm{AK}, \mathrm{TN}$, TK and organic matter (OM) contents in CK and fertilizer applied tea garden soil samples though TP and AP contents were higher in MRSC + GM treated tea garden soil (Figure 1).

\subsection{Abundance and Diversity of Bacterial and Fungal Species}

According to Hiseq sequencing data on the phylum level, Acidobacteria, Proteobacteria and Actinobacteria are the most abundant bacteria, and Ascomycota, Zygomycota and Basidiomycota are the most abundant fungi (Figure 2). The relative abundance of bacterial species was higher in organic fertilizer applied tea garden soil than inorganic or zero fertilizer treated tea garden soil samples except Acidobacteria which was lower in RSC and MRSC + GM treatment. Specifically, Chloroflexi bacterial species population was higher almost $50 \%$ in organic fertilizer (RSC) treated soil samples followed by other bacterial species. However, the abundance of Firmicutes was lower in RSC applied soil than 
other fertilizer treatments. For the fungi, very little Basidiomycota population was observed in MRSC + GM treated tea garden soil.

$\mathrm{PH}$

AHN

AP

AK
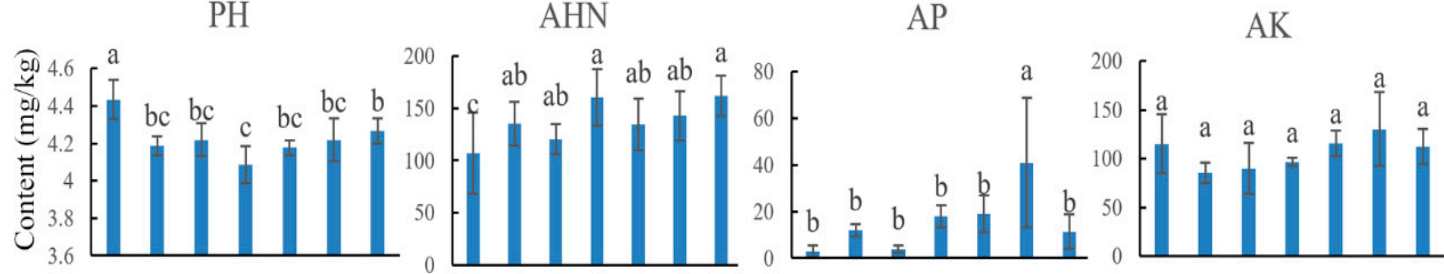

TN

TP

TK
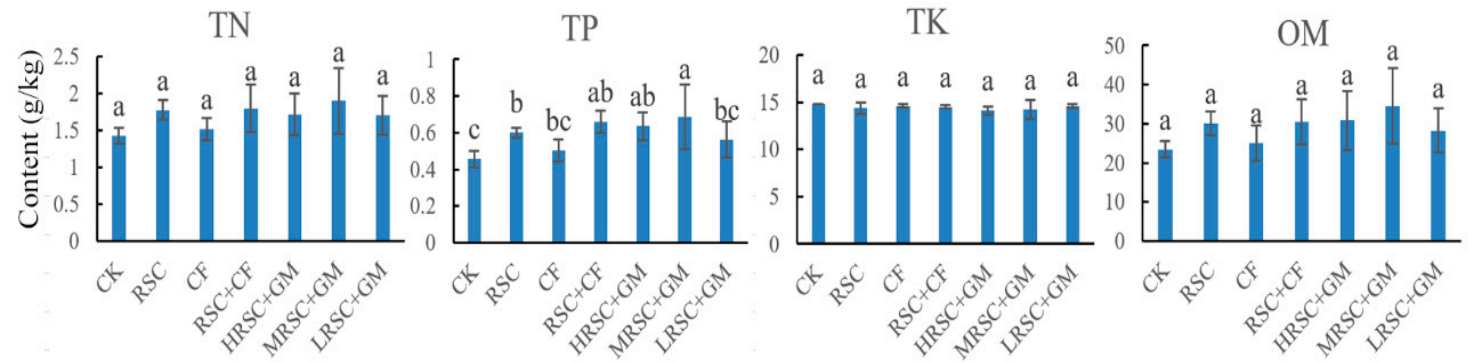

Fertilizer treatment

Figure 1. Soil physico-chemical properties from tea orchards with different fertilizer application.
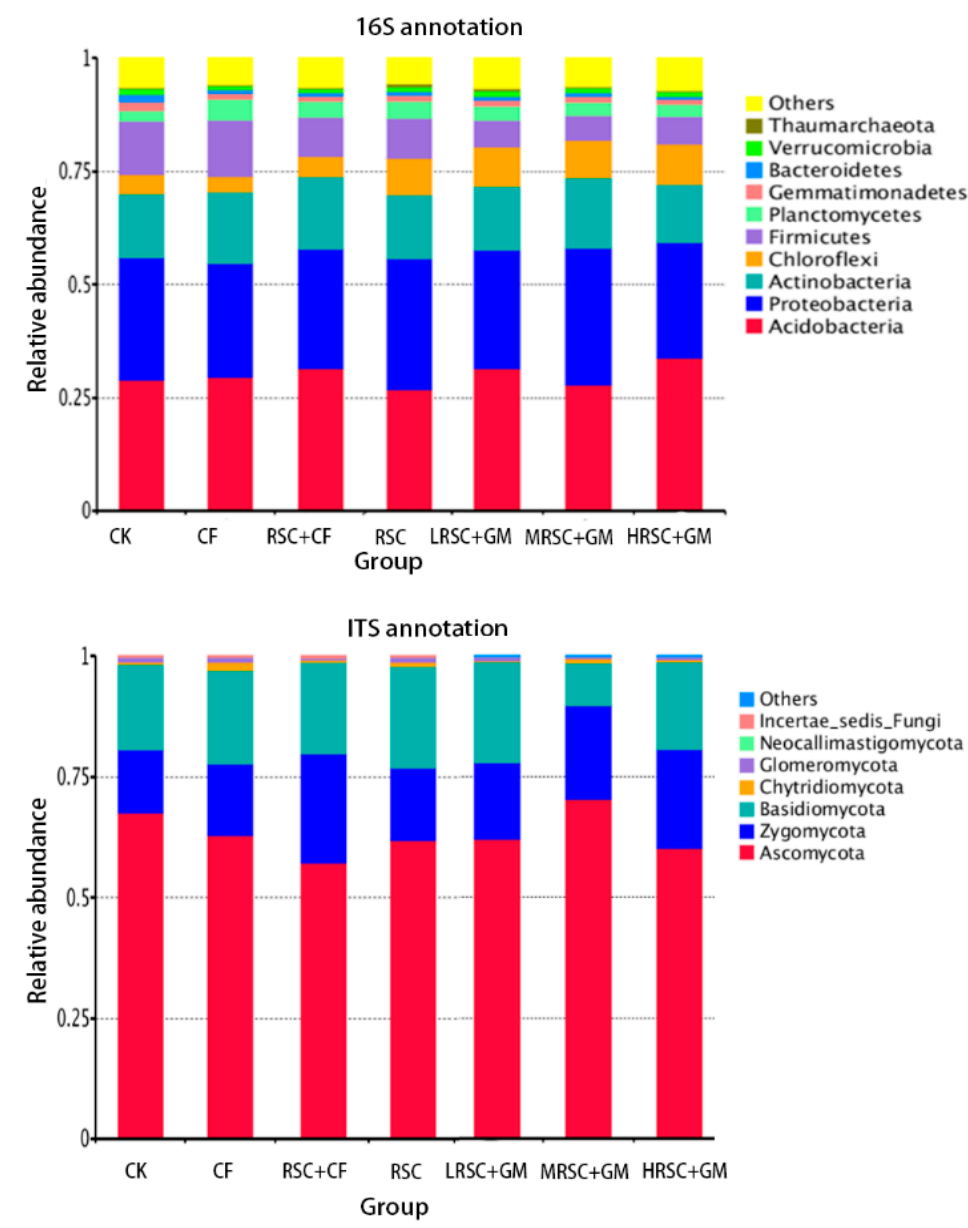

Figure 2. The abundant bacteria (16S rRNA annotation) and fungi (internal transcribed spacer (ITS) annotation) in soil of different fertilizer applied tea garden soil. 


\subsection{Abundance and Diversity of Microbes on Genus Level}

As shown in Figure 3, the significant level microbial population differences were observed between the fertilizer applied and zero fertilizer applied tea garden soil. In control tea garden soil, Haliangium, Sphingomonas, Gemmatimonas and Candidatus Solibacter are the dominant microbes. In inorganic fertilizer applied tea garden soil (CF), Acidothermus and Actinospica are the dominant microbial species. In organic fertilized soil (RSC), Mizugakiibacter, Kitasatospora and Mycobacterium were the most abundant microbes. In contrast, the abundance of microbes significantly changed in integrated application of RSC with different manures.

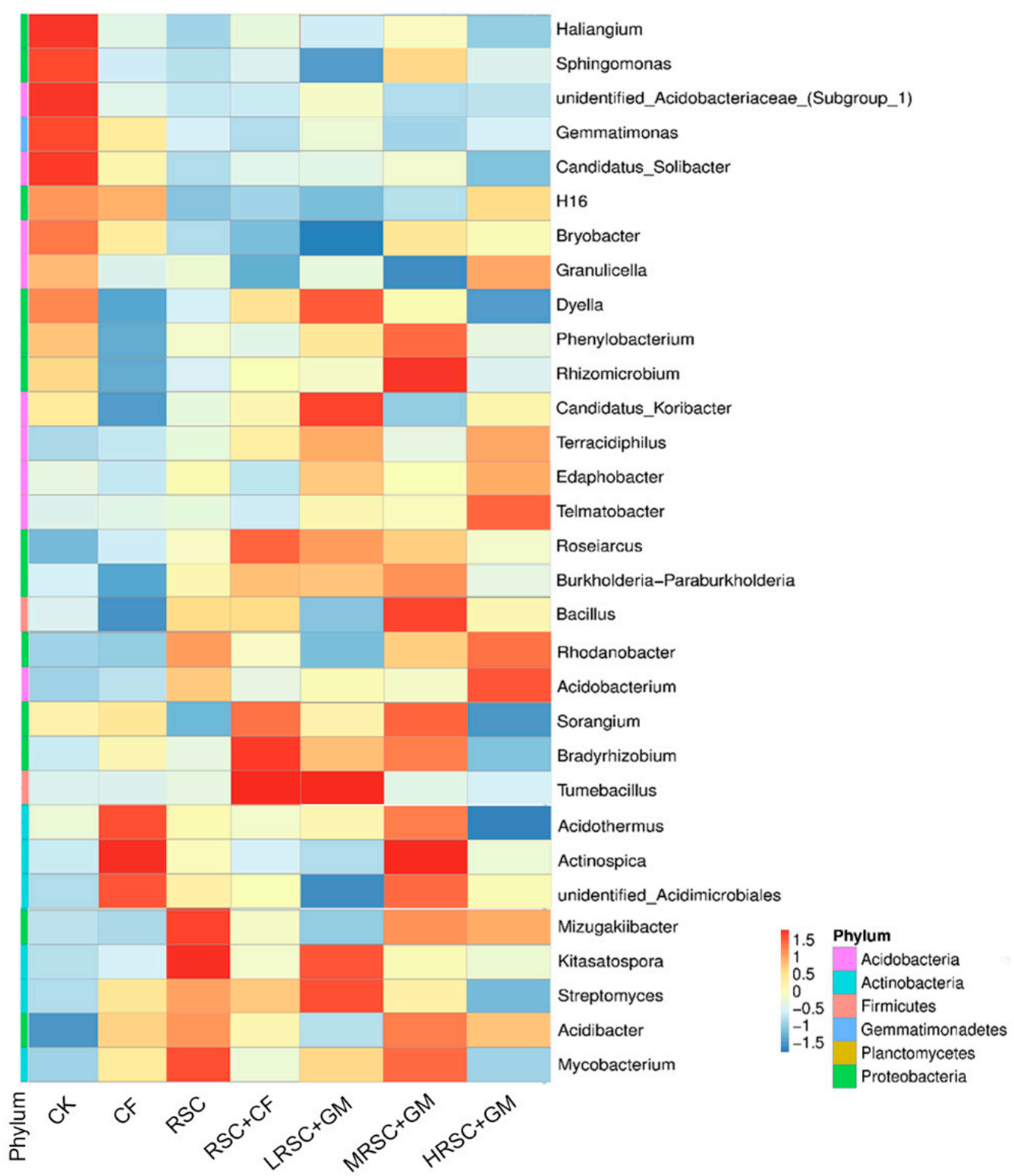

Figure 3. Top abundant microbes in different fertilizer applied tea garden soil on genus level.

\subsection{Correlation between Bacterial and Fungal Communities with Soil Properties}

The results revealed that the Acidibacter was positively correlated with AP and TP. Acidothermus was positively correlated to soil $\mathrm{pH}$, but had negative correlation with $\mathrm{AP}$, TN, TP and TOC (Figure 4). The Figure 5 showed that the Trichoderma spp., was positively correlated to AK. Myrmecridium had positive correlation with soil $\mathrm{pH}$ and $\mathrm{AK}$, but negative correlation to TP and the ratio of total organic carbon to total nitrogen $(\mathrm{CN})$. However, 
Climacodon had negative correlation with $\mathrm{pH}$ and $\mathrm{AK}$, but positive correlation with $\mathrm{TP}$ and TOC. In addition, Khuskia showed positive correlation with $\mathrm{pH}$, but negative correlation with TN and TP. Therefore, these fungal communities may be sensitive to the change of soil properties of tea garden.

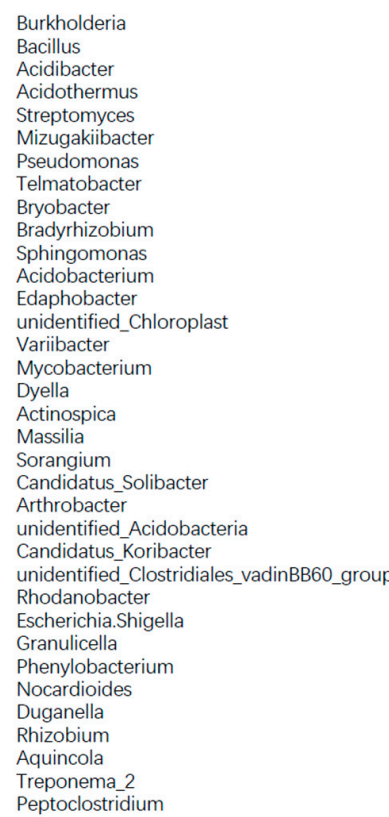

Peptoclostridium

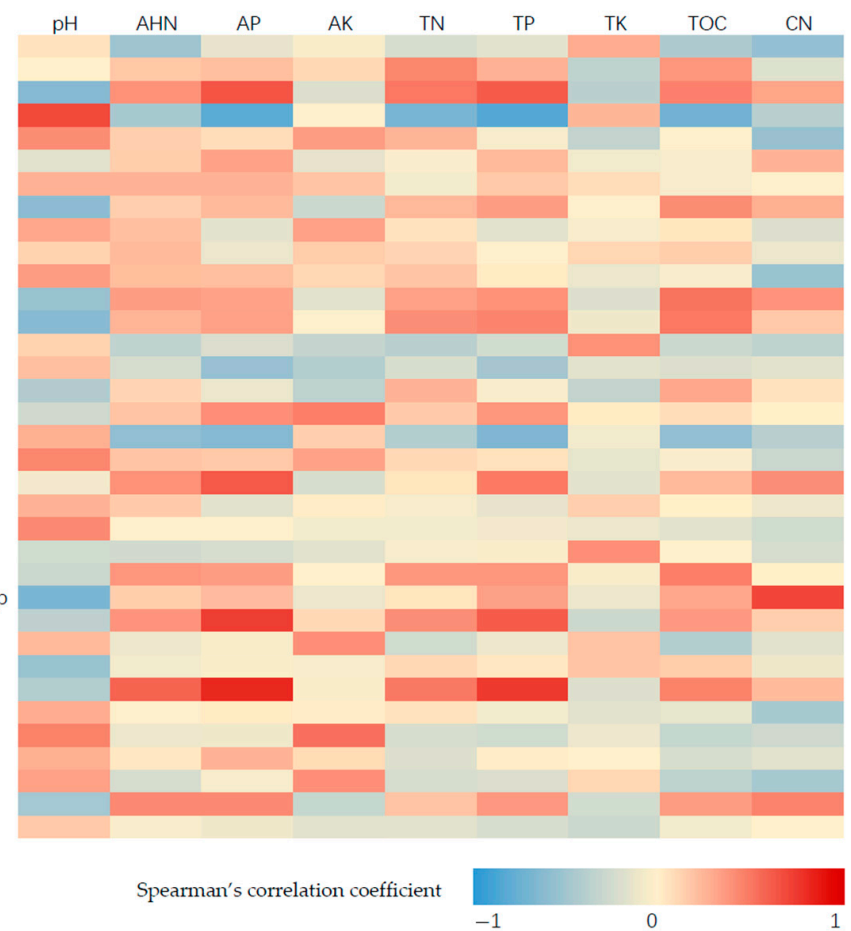

Figure 4. Spearman's correlation between bacterial communities and soil properties by different fertilizer treatment.

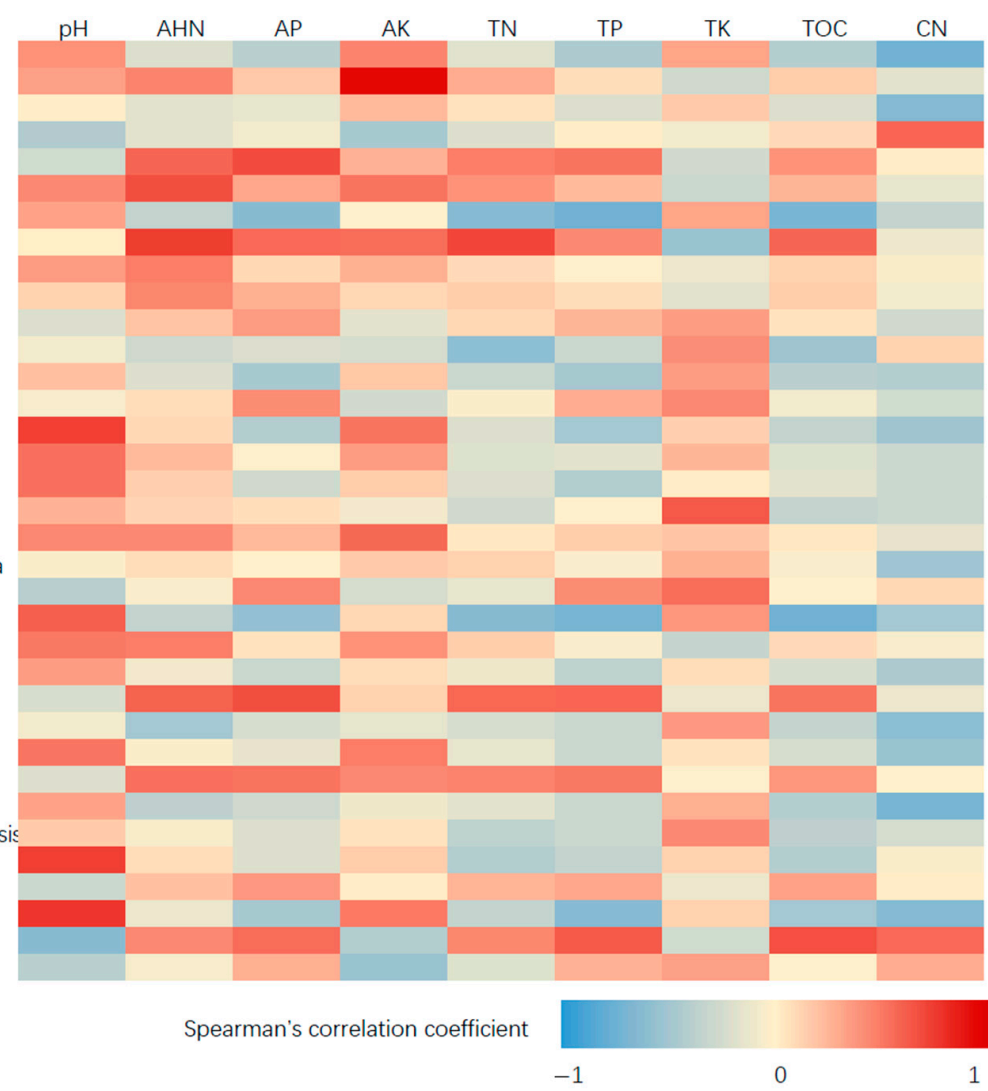

Figure 5. Spearman's correlation between fungal communities and soil properties by different fertilizer treatment. 


\section{Discussion}

The obtained data suggested that the strategic management of soil organic inputs could greatly affect the soil fertility of the tea garden. The influence of microbial consortia on the productivity of the plantation crops along with nutrient content of the soil is an interesting area of plantation crop research in recent days. Several agricultural crops and their associated microbial populations studied earlier indicate that some special group of microorganisms are associated with a particular group of plants that directly influence the growth of the crop plants and the tolerance to biotic and abiotic stresses on various aspects [24].

A few studies have been reported $[6,25]$ on the effect of fertilizer application on tea plantation correlated with microbial communities and soil biochemical properties. In the present study the influence of different organic and inorganic manures on the growth of soil microbial consortia was investigated. The obtained results suggest that Acidibacter and Acidothermus are important indicators for soil nutrient properties. This study showed the effects of different fertilizer application on soil properties and microbiota. The results indicated that fertilization increase the content of $\mathrm{AHN}$ but decrease $\mathrm{pH}$, organic fertilizer slightly increase the content of OM, MRSC + GM had a significant impact on TP and AP of soil. Besides, significant level of microbial abundance and diversity were observed in different fertilizer application. Correlation analysis revealed that bacteria such as Acidibacter and Acidothermus and the fungi including Myrmecridium, Climacodon and Khuskia were significantly associated the soil properties ( $\mathrm{pH}, \mathrm{TOC}, \mathrm{TN}, \mathrm{C} / \mathrm{N}, \mathrm{TP}, \mathrm{AP}$ and AK), which suggests that these microbes could be the indicators for soil nutrition status.

The increase in duration of continuous cropping years gradually altered soil chemical properties. Total $\mathrm{N}$ and $\mathrm{C}$, exchangeable $\mathrm{NH}^{4+}-\mathrm{N}$ were decreased. However, fertilizer practice may improve the quality of the tea orchard [26]. This study showed that organic fertilization could slightly increase the content of soil organic matter, AHN, TP and AP compare to no fertilizer and chemical fertilizer treatments. The chemical properties such as AP and TP were the most abundant elements compared to other fertilizer practices, which indicated that MRSC + GM could improve the TP and AP content in soil of tea garden. In inorganic fertilizer applied tea garden soil (CF), Acidothermus and Actinospica are the dominant microbial species. In organic fertilized soil (RSC), Mizugakiibacter, Kitasatospora and Mycobacterium were the most abundant microbes. In contrast, the abundance of microbes significantly changed in integrated application of RSC with different manures. Among all fertilizer treatments, MRSC + GM might be a potential fertilizer to improve soil microbial abundance, diversity, carbon and nutrient availability of tea garden.

Different fertilizer application has changed the abundance and structure of the microbiota in different soil ecosystem by different fertilizer practices. Of the physicochemical property measures, the Redundancy analysis showed that TOC had a significant effect $(p<0.05)$ on bacterial community in tea orchard. Proteobacteria, Acidobacteria, Chloroflexi and Actinobacteria were the dominant phyla in fertilizer soils, which was in accordance with the results of $[8,27]$. The results showed that Proteobacteria, Acidobacteria, Chloroflexi and Actinobacteria in the soil bacterial flora had strong growth ability in tea garden soil. Compared to other fertilization treatments, MRSC + GM increased the relative abundance of Acidobacteria, Proteobacteria and Actinobacteria in the soil. Acidobacteria were the most abundant phyla in soil but with very low availability [28]. Proteobacteria and Acidobacteria can promote the degradation and decomposition of straw in soil [29-31]. At genus level, Acidibacter and Acidothermus were associated to soil nutrient properties, and both bacteria were enriched in MRSC + GM treated soil. Thus, both bacteria were important to maintain the soil environment of tea plants. There are many bacteria which affect the nutrient in soil [32,33]. For examples, the extensively examined Rhizobium is a symbiotic bacterium of leguminous plants. $\mathrm{N}_{2}$-fixation is the vital role of Rhizobia for plants. The $\mathrm{N}_{2}$ fixed by Rhizobia in legumes is also beneficial to the intercrops via direct transfer of biologically fixed N. Thus, legumes were usually used as green manure planted in tea garden. Previous studies have identified that Acidobacterium occurred in diverse environments as a dominant 
bacterial group $[34,35]$. The use of the measured physicochemical properties for fertility index calculation allows us to decipher the effects of soil fertility on the bacterial and fungal community in tea plantation soils.

\section{Conclusions}

Based on 3-year uninterrupted field experiment, dynamic effect was understood well about organic amendments supplementation on soil quality, which provides scientific basis for agriculture practice. Our field experiments showed that fertilizer treatments had no significant effect on TK. Compared with complete chemical fertilizer and no fertilizer application, organic fertilizer slightly increase the content of soil OM, TN and TP, significantly increased AHN and AP, but slightly reduced soil $\mathrm{pH}$. In addition, our results found that bacteria such as Acidibacter and Acidothermus and the fungi including Myrmecridium, Climacodon and Khuskia were significantly associated the soil properties $(\mathrm{pH}, \mathrm{TOC}, \mathrm{TN}, \mathrm{C} / \mathrm{N}, \mathrm{TP}$, $\mathrm{AP}$ and $\mathrm{AK}$ ), which suggests that these microbes could be the indicators for soil nutrition status. Among all fertilizer treatments, MRSC + GM might be a potential fertilizer to improve soil microbial abundance, diversity, carbon and nutrient availability of tea garden.

\section{Patents}

This section is not mandatory but may be added if there are patents resulting from the work reported in this manuscript.

Author Contributions: Conceptualization, methodology, investigation, software, validation, resources, data curation, writing-original draft preparation, H.F., H.L.; resources, formal analysis, data curation, writing — original draft preparation, P.Y., H.M. and J.L.; investigation, P.Z., Y.W.; methodology, data curation, writing-review, Q.M., A.J., K.T. and X.C.; conceptualization, supervision, writing - review, editing and funding, X.L.; supervision, funding acquisition, G.G. All authors have read and agreed to the published version of the manuscript.

Funding: This research was funded by National Key R\&D program (2016YFD0200900), the Natural Science Foundation of Jiangsu Province (BK20200554), the National Natural Science Foundation of China (31800590), Special Fund for Agro-scientific Research in the Public Interest (201503110), the Nanjing special plan for Shangluo leading industry demand (20201105), the Open Fund of Henan Key Laboratory of Tea Plant Comprehensive Utilization in South Henan (HNKLTOF2020002), the China Earmarked Fund for Modern Agro-industry Technology Research System (CARS-19) and Expert Workstation of Yunnan Cuigong Tea Co., Ltd. (Zhaotong, China) in Zhaotong (2020ZTYX07).

Institutional Review Board Statement: The study was conducted according to the guidelines of the Declaration of Helsinki, and approved by the Institutional Review Board of Sustainability Editorial Office.

Informed Consent Statement: Informed consent was obtained from all subjects involved in the study.

Acknowledgments: We thank Yuehua Ma (Central laboratory of College of Horticulture, Nanjing Agricultural University) for using PCR (T100, Bio-rad, Hercules, CA, USA).

Conflicts of Interest: The authors declare no conflict of interest.

\section{References}

1. Karlen, D.; Mausbach, M.; Doran, J.; Cline, R.; Harris, R.; Schuman, G. Soil quality: A concept, definition, and framework for evaluation (a guest editorial). Soil Sci. Soc. Am. J. 1997, 61, 4-10. [CrossRef]

2. Liu, M.; Hu, F.; Chen, X.; Huang, Q.; Jiao, J.; Zhang, B.; Li, H. Organic amendments with reduced chemical fertilizer promote soil microbial development and nutrient availability in a subtropical paddy field: The influence of quantity, type and application time of organic amendments. Appl. Soil Ecol. 2009, 42, 166-175. [CrossRef]

3. Smith, J.; Paul, E.; Bollag, J.; Stotzky, G. The significance of soil microbial biomass estimations. Soil Biochem. 1990, 6, $357-396$.

4. Steenwerth, K.L.; Jackson, L.E.; Calderón, F.J.; Stromberg, M.R.; Scow, K.M. Soil microbial community composition and land use history in cultivated and grassland ecosystems of coastal California. Soil Biol. Biochem. 2002, 34, 1599-1611. [CrossRef]

5. Shen, J.P.; Zhang, L.M.; Guo, J.F.; Ray, J.L.; He, J.Z. Impact of long-term fertilization practices on the abundance and composition of soil bacterial communities in Northeast China. Appl. Soil Ecol. 2010, 46, 119-124. [CrossRef] 
6. Xue, D.; Huang, X.; Yao, H.; Huang, C. Effect of lime application on microbial community in acidic tea orchard soils in comparison with those in wasteland and forest soils. J. Environ. Sci. 2010, 22, 1253-1260. [CrossRef]

7. Li, Y.; Li, Z.; Arafat, Y.; Lin, W.; Jiang, Y.; Weng, B.; Lin, W. Characterizing rhizosphere microbial communities in long-term monoculture tea orchards by fatty acid profiles and substrate utilization. Eur. J. Soil Biol. 2017, 81, 48-54. [CrossRef]

8. Li, Y.; Li, Z.; Li, Z.W.; Jiang, Y.; Weng, B.Q.; Lin, W.X. Variations of rhizosphere bacterial communities in tea (Camellia sinensis L.) continuous cropping soil by high-throughput pyrosequencing approach. J. Appl. Microbiol. 2016, 121, 787-799. [CrossRef]

9. Galloway, J.N.; Aber, J.D.; Erisman, J.W.; Seitzinger, S.P.; Howarth, R.W.; Cowling, E.B.; Cosby, B.J. The nitrogen cascade. AIBS Bull. 2003, 53, 341-356. [CrossRef]

10. Lin, W.X.; Chen, T.; Zhou, M.M. New dimensions in agroecology. Chin. J. Eco-Agric. 2012, 20, 253-264. [CrossRef]

11. Drescher, G.L.; da Silva, L.S.; Sarfaraz, Q.; dal Molin, G.; Marzari, L.B.; Lopes, A.F.; Cella, C.; Facco, D.B.; Hammerschmitt, R.K. Alkaline hydrolyzable nitrogen and properties that dictate its distribution in paddy soil profiles. Pedosphere 2020, 30, 326-335. [CrossRef]

12. Keeney, D.R.; Nelson, D.W. Nitrogen-Inorganic Forms 1. In Methods of Soil Analysis. Part 2. Chemical and Microbiological Properties, 2nd ed.; Miller, R.H., Keeney, D.R., Eds.; Agronomy 9/2; American Society of Agronomy: Madison, WI, USA, $1982 ;$ pp. 643-698.

13. Bao, S.D. Soil and Agricultural Chemistry Analysis; China Agriculture Press: Beijing, China, 2000.

14. Wang, L.; Sun, X.; Li, S.; Zhang, T.; Zhang, W.; Zhai, P. Application of organic amendments to a coastal saline soil in north China: Effects on soil physical and chemical properties and tree growth. PLoS ONE 2014, 9, e89185. [CrossRef]

15. Pansu, M.; Gautheyrou, J. Handbook of Soil Analysis: Mineralogical, Organic and Inorganic Methods; Springer Science \& Business Media: Berlin/Heidelberg, Germany, 2007.

16. Dineen, S.M.; Aranda IV, R.; Anders, D.L.; Robertson, J.M. An evaluation of commercial DNA extraction kits for the isolation of bacterial spore DNA from soil. J. Appl. Microbiol. 2010, 109, 1886-1896. [CrossRef]

17. Liu, B.; Yuan, J.; Yiu, S.M.; Li, Z.; Xie, Y.; Chen, Y.; Shi, Y.; Zhang, H.; Li, Y.; Lam, T.W. COPE: An accurate k-mer-based pair-end reads connection tool to facilitate genome assembly. Bioinformatics 2012, 28, 2870-2874. [CrossRef]

18. Caporaso, J.G.; Kuczynski, J.; Stombaugh, J.; Bittinger, K.; Bushman, F.D.; Costello, E.K.; Fierer, N.; Peña, A.G.; Goodrich, J.K.; Gordon, J.I.; et al. QIIME allows analysis of high-throughput community sequencing data. Nat. Methods 2010, 7, 335-336. [CrossRef] [PubMed]

19. Edgar, R.C.; Haas, B.J.; Clemente, J.C.; Quince, C.; Knight, R. UCHIME improves sensitivity and speed of chimera detection. Bioinformatics 2011, 27, 2194-2200. [CrossRef] [PubMed]

20. Haas, B.J.; Gevers, D.; Earl, A.M.; Feldgarden, M.; Ward, D.V.; Giannoukos, G.; Ciulla, D.; Tabbaa, D.; Highlander, S.K.; Sodergren, E.; et al. Chimeric 16S rRNA sequence formation and detection in Sanger and 454-pyrosequenced PCR amplicons. Genome Res. 2011, 21, 494-504. [CrossRef] [PubMed]

21. Edgar, R.C. UPARSE: Highly accurate OTU sequences from microbial amplicon reads. Nat. Methods 2013, 10, 996-998. [CrossRef] [PubMed]

22. Kõljalg, U.; Nilsson, R.H.; Abarenkov, K.; Tedersoo, L.; Taylor, A.F.; Bahram, M.; Bates, S.T.; Bruns, T.D.; Bengtsson-Palme, J.; Callaghan, T.M.; et al. Towards a unified paradigm for sequence-based identification of fungi. Mol. Ecol. 2013, 22, 5271-5277. [CrossRef]

23. Edgar, R.C. MUSCLE: Multiple sequence alignment with high accuracy and high throughput. Nucleic Acids Res. 2004, 32, 1792-1797. [CrossRef]

24. Kumar, A.; Dubey, A. Rhizosphere microbiome: Engineering bacterial competitiveness for enhancing crop production. J. Adv. Res. 2020, 24, 337-352. [CrossRef]

25. Piao, H.; Hawley, E.; Kopf, S.; DeScenzo, R.; Sealock, S.; Henick-Kling, T.; Hess, M. Insights into the bacterial community and its temporal succession during the fermentation of wine grapes. Front. Microbiol. 2015, 6, 809. [CrossRef]

26. Yuan, H.; Ge, T.; Zhou, P.; Liu, S.; Roberts, P.; Zhu, H.; Zou, Z.; Tong, C.; Wu, J. Soil microbial biomass and bacterial and fungal community structures responses to long-term fertilization in paddy soils. J. Soils Sediments 2013, 13, 877-886. [CrossRef]

27. Zhang, W.; Zhang, G.; Liu, G.; Dong, Z.; Chen, T.; Zhang, M.; Dyson, P.J.; An, L. Bacterial diversity and distribution in the southeast edge of the Tengger Desert and their correlation with soil enzyme activities. J. Environ. Sci. 2012, 24, $2004-2011$. [CrossRef]

28. Fierer, N.; Bradford, M.A.; Jackson, R.B. Toward an ecological classification of soil bacteria. Ecology 2007, 88, 1354-1364. [CrossRef] [PubMed]

29. Stark, C.; Condron, L.M.; Stewart, A.; Di, H.J.; O'Callaghan, M. Influence of organic and mineral amendments on microbial soil properties and processes. Appl. Soil Ecol. 2007, 35, 79-93. [CrossRef]

30. Herbert, R. Nitrogen cycling in coastal marine ecosystems. FEMS Microbiol. Rev. 1999, 23, 563-590. [CrossRef]

31. Espenberg, M.; Truu, M.; Mander, Ü.; Kasak, K.; Nõlvak, H.; Ligi, T.; Oopkaup, K.; Maddison, M.; Truu, J. Differences in microbial community structure and nitrogen cycling in natural and drained tropical peatland soils. Sci. Rep. 2018, 8, 4742. [CrossRef] [PubMed]

32. Hayat, R.S.; Ali, S.; Siddique, M.T.; Chatha, T.H. Biological nitrogen fixation of summer legumes and their residual effects on subsequent rainfed wheat yield. Pak. J. Bot. 2008, 40, 711-722.

33. Hayat, R.; Ali, S.; Amara, U.; Khalid, R.; Ahmed, I. Soil beneficial bacteria and their role in plant growth promotion: A review. Ann. Microbiol. 2010, 60, 579-598. [CrossRef] 
34. Chan, O.C.; Yang, X.; Fu, Y.; Feng, Z.; Sha, L.; Casper, P.; Zou, X. 16S rRNA gene analyses of bacterial community structures in the soils of evergreen broad-leaved forests in south-west China. FEMS Microbiol. Ecol. 2006, 58, 247-259. [CrossRef] [PubMed]

35. Kim, J.S.; Lee, K.C.; Kim, D.S.; Ko, S.H.; Jung, M.Y.; Rhee, S.K.; Lee, J.S. Pyrosequencing analysis of a bacterial community associated with lava-formed soil from the Gotjawal forest in Jeju, Korea. MicrobiologyOpen 2015, 4, 301-312. [CrossRef] [PubMed] 